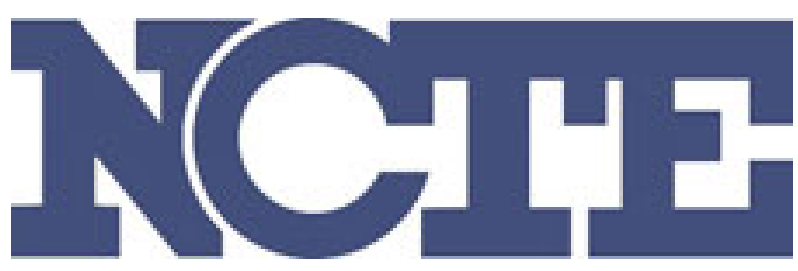

Teacher to Teacher: What Is a Good Activity for Teaching World Literature to High School Students?

Author(s): Elaine Razzano, Anna E. Baldwin, Lewis Cobbs, Sandra Whitaker, Jessica Parker and Frank J. Krajcovic

Reviewed work(s):

Source: The English Tournal, Vol. 91, No. 5, The World of Literature (May, 2002), pp. 24-27

Published by: National Council of Teachers of English 


\section{What Is a Good Activity for Teaching World Literature to High School Students?}

\section{Elaine Razzano \\ Lyndon State College \\ Lyndonville, Vermont \\ razzanoe@mail.Isc.vsc.edu}

"I thought this was a literature class, not a geography class!" This complaint is what I sometimes hear the first day of my world literature course. That's because I situate the literature in a geographical context, knowing that most of my students have no sense of direction when it comes to foreign countries. I start with two prereading activities.

My most useful "prop" for this class is a world map. It remains on the front classroom wall throughout the course and serves as a visual reference point for the literature that we study. However, before I display it, I hand out outlines of a world map to the students and ask them to identify the seven continents. Most students can do this easily, but they falter when I ask them to write in the names of three countries for any three of the continents they identified on the map. As an alternative, I sometimes give the students the names of three countries whose literature they'll be reading in class and have them write the names with their respective continents. This activity helps students establish a sense of place, a way of visualizing the physical world, even if only on a map. As the course progresses, students eventually learn how geography and human culture complement each other.

The other activity requires travel guidebooks (such as those published by Lonely Planet, Fodor, and Frommer) and a worksheet of my own design. The guidebooks (National Geographic magazines can also be used) typically focus on one or more specific countries whose literature the students will read in my class. In small groups, students find answers to questions on the worksheet: What is the ed- ucation system like? What religion predominates? How do people earn a living? The number of questions should be the same for every country, although the kind of information sought may vary, depending on the content of the particular guidebook or magazine. After completing their worksheets, the groups present their findings to the class and answer any relevant questions posed by their classmates. This activity, combined with the map outline, piques students' interest in other countries and cultures of the world and prepares them to enter those worlds through literature.

\section{Anna E. Baldwin \\ Two Eagle River School \\ Pablo, Montano \\ jabaldwin@blackfoot.net}

This idea for teaching world literature came to me when I discovered that most of my students didn't know what a passport was and apparently had never visited another country. For this unit, I had my students create passports for use in the classroom. Then, as we read short stories and poetry from different world authors, students got a "stamp" from each country they "visited."

First, I brought in my passport and showed them what a real one looks like, with the picture, the biographical information page, and the stamps from different countries. Then I used a camera-digital or Polaroid will work - to take mug shots, and students wrote down basic information such as full name, birth date, and place of birth on an index card. I used the pictures and their information to make the biographical pages on my computer. They used blue construction paper for the covers and some extra white paper for the pages of their passports. Before stapling their booklet together, with bio- 
graphical printout in front, the students placed contact paper on the covers to achieve a laminated look.

For the stamps, I found a Web site with illustrations of all the flags of the world; I used the tiny pictures and the countries' names to make labels and printed them on label sheets. Another idea for creating stamps might consist of students researching countries and designing their own illustrations.

I closed this unit with an assignment for each student to create a PowerPoint presentation on a country of choice. Other extension ideas might include creating a travel diary to go with the passport, reading and writing newspaper articles about the countries students are "visiting," and creating a passport to various states in our own country. Because I teach at a tribal school, I may create a Passport to Indian Country unit and "visit" various tribes that way.

Students enjoyed the creative aspect of this activity and couldn't wait to fill their pages with stamps.

\section{Lewis Cobbs \\ Randolph School \\ Huntsville, Alabama \\ Icobbs@randolphschool.net}

Whether taught within a thematic block or as a stand-alone unit in a course centered on world literature, Chinua Achebe's Things Fall Apart (Doubleday/Anchor Books, 1959) forces students to question their assumptions about the meaning of "culture" and "civilization." With a narrative consciousness grounded in the values of Ibo life during the years just prior to and immediately following contact with Europeans, the novel presents as familiar-as given-beliefs and practices that will be utterly foreign to young Western readers. Yet the world Achebe depicts is not only completely coherent, but also fully human.

Written in a deceptively simple style-the language of a storyteller transmitting lore-Things Fall Apart is readily approachable for almost any high school reader. Discussion might first concentrate on clues the narrator gives us about the culture in which he lives. Careful scrutiny will reveal, for instance, that within the first chapter alone the speaker shifts time perspective at eleven different points: immediately Achebe has isolated the presence of the past and a cyclical sense of time as defining values for the narrator's society. As the author continues to unfold Ibo culture, students might map corresponding and contrasting traits of Western societies. Classes that read Things Fall Apart in conjunction with Conrad's Heart of Darkness (Penguin Putnam/Signet Classics, 1997) will be struck by the diametrically opposed treatment of parallel images-most notably, drumming and headhunting - in the two novels.

By the time they have read half the novel, students will be able to focus on major issues: the integrity of Ibo culture, and the limitations of viewing, much less judging, non-Western ways of life simply from the perspective of Western values. Developments in the second half of the book will intensify the debate. The arrival of Europeans and the disintegration of traditional Ibo life challenge Western readers to see themselves with African eyesand, by looking from the outside, to reexamine the values that give them identity.

Things Fall Apart offers rich opportunities for writing. Students might tell a new story in a voice modeled on that of the novel's narrator; compose a letter, journal, or report in the style of an English colonist; study west African art, religion, or social structure in a short research paper; or compare or contrast representations of Western and non-Western culture in Things Fall Apart and another work with related concerns such as Heart of Darkness, James Welch's Fools Crow (Penguin Books, 1986), Brian Moore's Black Robe and/or Bruce Beresford's 1991 film of that novel (Dutton, 1985; Samuel Goldwyn, 1991), or Barbara Kingsolver's The Poisonwood Bible (HarperCollins, 1998).

\section{Sandra Whitaker \\ The Independent School \\ Wichita, Kansas \\ switaker@kscable.com}

For the past two years, I have taught in a ninth grade reading immersion program. The students qualify for this program by testing in the fortieth percentile on standardized tests, maintaining a solid attendance record, and having a teacher recommendation. From these students I have learned the importance of hands-on activities to explore themes in literature.

One activity that allows my students to better understand consequences of actions, themes in literature, and sequence of events is "Antigone's Dirty Laundry." In preparation for this activity, I gave each student a graphic organizer with spaces to indicate the character's initial action (who did 
what), the effect of that action on other characters and events, and the final result/consequence of the action. For example, Creon's refusing to listen to Haemon's appeal on Antigone's behalf affects Antigone because she is sentenced to death; Haemon, because he is engaged to Antigone and becomes grief-stricken, consequently commits suicide. Ultimately, Creon banishes himself and becomes a nonperson in society as a result of his poor judgment.

After completing the graphic organizer, students, using fabric paint pens, transfer the information from their graphic organizers, using pictures to depict the various scenes, onto a piece of laundry. Because each student begins with a different event/ incident of immorality, each piece of laundry is different, allowing students to see in pictures the various events and consequences in the play. I then hang the "dirty laundry" from a rope strung across my classroom. (This is a great way for students to review the play each day as they come into class.) As we aired "Antigone's dirty laundry," students learned to trace actions and themes through a difficult play.

\section{Jessica Parker \\ University of California, Berkeley ipar9@hotmail.com}

I wanted a student-centered activity to introduce Alan Paton's Cry, the Beloved Country (Macmillan, 1948) to my tenth grade World Literature classes. My prereading goals were to access the background knowledge of students, dissect the system of apartheid within South Africa, review the history of the country, and address some of South Africa's current events. Station rotation, long used by physical education teachers, was my answer.

Station rotation places students in groups and asks them to analyze information (texts, pictures, objects, etc.) at their prescribed station. Students are given a worksheet and, working collectively, they answer the designated questions. After a period of time determined by the teacher, students rotate to the next station and continue with their analyses.

In the Cry, the Beloved Country station rotation, students discover important facts and themes by examining texts, pictures, and currency. For instance, station \#1 uses materials from the Bureau of Public Affairs to introduce the history of South Africa: apartheid, government, and people. Another station presents black-and-white photos to discuss the diamond mines, the protests of apartheid, and race relations. In addition, station \#5 shows currency from South Africa, which is printed in English and Afrikaans and portrays the Dutchman, Jan van Riebeeck. By the end of the activity, students have skimmed newspaper articles, defined and summarized key concepts, and scrutinized primary and secondary source documents.

By combining higher order thinking skills such as assessment, evaluation, and discussion with listing, defining, and identifying, station rotation forces students to use a variety of skills during the class period. This type of pedagogy creates a dialogue among students and their texts and allows students to elicit and develop schema integral to the unit. Building a station rotation does take time, but the effects are worth every ounce of effort.

\section{Frank J. Krajcovic \\ Woodland Park High School \\ Woodland Park, Colorado \\ merryslav@yahoo.com}

World literature means just that: literature from all over the world. I usually start with Africa and have the students brainstorm what they know about the continent. We put a list of twenty or thirty items on the board, and then discuss how some of them might affect what is written in modern African literature. From there, we come up with a list of potential themes to look for. We read stories by Chinua Achebe, Nadine Gordimer, Bessie Head, and others. Before we leave Africa, each student writes a paper tying some of the stories, poems, and perhaps a movie to one of the expected themes (or even an unexpected theme, if a student is clever enough to discover one). The essays are expected to be of high quality, and we work on them until they are.

When we move to the Far East, the first thing I try to do is expose the students to an eastern way of looking at things. We look at the teachings of Confucius and Lao-tze, perhaps some Buddhist koans or stories (perhaps even just quotations from The Little Zen Calendar). We talk about the Eastern tradition of doing simple things exquisitely—the Japanese garden, the Japanese tea ceremony, origami. From there we easily move into haiku and tanka poetic forms and a Noh play.

We then look at modern Chinese literature, again anticipating themes based on what we know about China and its history. Some wonderful literature has come out of China recently-much of it 
critical of communist rule. (Some of the stories are set in the prison camps that housed the intelligentsia.) However, there are also good stories by writers who believed in communism and wrote with government approval. It is interesting to have the class compare the two.

After the Far East, we go to India, again beginning with what we know about the country and boiling that down to expected themes. Some of the old writings are either religious (The Bhagavad-Gita) or fantastic (The Panchanantra) in nature. Some are more realistic and can either be funny-R. K. Narayan's “A Horse and Two Goats," or soberingMahasweta Devi's "Dowli." Some can have elements of both-Ruth Prawer Jhabvala's "The Interview."

Latin America has wonderful, brilliant, imaginative writers like Jorge Luis Borges, Gabriel
Garcia Marquez, and Julio Cortazar, as well as great realistic writers like Isabel Allende and Carlos Fuentes. Students have their eyes opened by this dichotomy. I can usually find a student in each class whom I can challenge by asking her or him to do a research presentation on magic realism.

Eventually we make it to Europe and Eurasia, where there are great distinctions in each nation's literature. Depending on the time we have, we either visit many countries as a class, or else I splinter the class and have different groups read literature from different European countries and report back to the others. I choose a few authors from the British canon that I can present wellBurns, Blake, Browning—and we celebrate as much as we can.

\section{answers for MORE THAN ENOUGH (page 23)}
$\begin{array}{lll}\text { 1. INCANDESCENT } & \text { 2. PANORAMA } & \text { 3. ABANDON }\end{array}$
4. DELLCATELY 5. CODEPENDENT
6. PERISCOPE 7. CORNERSTONE
8. NEEFECTUALITY
9. ElSEWHERE 10.
ROCKETSHIP 11. INDUSTRY 12. MENINGITIS
13. INJUSTICE 14. MARTYRED
15. MAHOGANY
16. UMPTEENTH
17. MONOTONE
18. FORESHADOWING
19. PeTROLEUM 20. PROUNOUNCEMENT 21. DECREPTT 22. SACRAMENTS
23. INTERMISION 24. PARENTHESES
25. OMNIBUSES
26. INTRODUCE

\section{EJ 25 years AGo}

\section{Establishing a Philosophy of Education}

To respond to the education critics and to deepen our own understanding of the human significance of our work, we must discuss, study, and work together to clarify what should be the guiding principles of education. It is not enough to have a few vague but noble goals posted up on the walls of the main office. If a philosophy of education is to have any real value, it must be constantly used as a criteria for self-evaluation of our own work. A philosophy of education must be applied to both curriculum content and teaching methods. 